\title{
Use of sodium-glucose cotransporter-2 inhibitors and urinary tract infections in type 2 diabetes patients: a systematic review
}

\author{
Izabela Rodrigues Figueiredo 1,3 \\ (iD) Sara Cardoso Paes Rose ${ }^{1,3}$ \\ (iD) Nathália Bandeira Freire ${ }^{1,3}$ \\ (iD) Marina Stabile Patrocínio ${ }^{1,3}$ \\ (iD) Natália Pierdoná ${ }^{1,3}$ \\ Roberto José Bittencourt ${ }^{2,3}$
}

1. Graduate program in Medicine, Catholic University of Brasília, Brasília (DF), Brasil 2. Coordinator of the Medical Clinic Internship of the Graduate program in Medicine, Catholic University of Brasília, Brasília (DF), Brasil 3. Catholic University of Brasília, Brasília (DF), Brasil

\section{SUMMARY}

Sodium-glucose cotransporter-2 inhibitors (SGLT2i) are drugs that act by maintaining glycosuria. Recent studies have shown promising effects of these in the treatment of type 2 diabetes mellitus (DM2). However, there may be an increased risk of developing urinary tract infections (UTIS) in patients treated with these. Our study aims to analyze the association between the risk of UTI in patients treated with SGLT2i. A systematic review of the literature was carried out by randomized clinical trials, totalizing at the end of the selection 23 articles that were statistically evaluated. The incidence of UTI was generally demonstrated in articles and in different subgroups: patients on SGLT2i monotherapy or on combination therapy; according to specific comorbidities of each sample or according to the drug used. They noticed an increase in the chance of UTI in the SGLT2i groups compared to the control groups on placebo or other oral antidiabetic agents. This increased chance was found predominantly with the use of Dapagliflozin, Canagliflozin, and Tofogliflozin, regardless of the dosing. Lastly, stands out that the dimension of UTI chances for DM2 patients who use SGLT2i remains to be more strictly determined.

KEYWORDS: Sodium-glucose transporter 2 antagonists/inhibitors. Diabetes mellitus, type 2. Urinary tract infections.

\section{INTRODUCTION}

The type 2 diabetes mellitus (DM2) accounts for approximately $90-95 \%$ of the diabetes cases worldwide. Its pathophysiology results from a combination of genetic, environmental and metabolic factors that initiate a state of hyperglycemia in the subject from peripheral insulin resistance and progressive failure of beta cells, resulting in decreased secretion of insulin by the pancreas., ${ }^{1,2}$

The pharmacological therapies, although effective in the glycemic control, sometimes present limitations that condition their use by patients. For this reason, new therapeutic agents are frequently researched. The sodium-glucose cotransporter-2 inhibitors (SGLT2i) propose an alternative therapy for DM2 based on an innovative mechanism substantiated on the renal importance of plasma glucose reabsorption. ${ }^{1,3}$

The kidney reabsorbs the filtered glucose through sodium-glucose cotransporters (SGLT 1 and 2) located in the tubular epithelium. In the proximal contort- 
ed tubule, SGLT2 is responsible for the reabsorption of $90 \%$ of the filtered glucose. The action of SGLT2i is based on the inhibition of this transport, which reduces renal reabsorption of glucose and induces through the increase of glycosuria a decrease in the plasma glucose of the diabetic patient. ${ }^{3,4}$

Some studies consider SGLT2i a promising therapeutic solution in the treatment of DM2. Given their mechanism of action independent of insulin, these can be used at any stage of the disease progression, with possible advantages such as decreased glycated hemoglobin, decreased fasting and postprandial glucose, weight reduction, blood pressure lowering and prevention of micro and macrovascular complications of diabetes, therefore improving the patient's quality of life. However, in these same studies that prove the efficacy of SGLT2i, cases of genito-urinary infection have also been observed in users; an effect that binds to glycosuria induced by SGLT2-1. ${ }^{1-4}$

The aim of this article was to review the association between the use of SGLT2i in patients with DM2 and the development of urinary tract infections (UTI) to estimate and analyze the risk of this adverse effect on the therapeutic approach.

\section{METHODS}

A systematic computerized search was performed using the following databases: PubMed (Public MEDLINE - Medical Literature Analysis and Retrieval System Online - US National Library of Medicine National Institutes of Health), SciELO (Scientific Electronic Library Online) and Cochrane Library. Keywords included "sodium glucose cotransporter-2 inhibitors", "diabetes mellitus type 2" and "urinary tract infection". The following filters were also used in the search: "clinical trials", "randomized," and "human". The results of the search process are described below (Figure 1).

Study selection was completed using the PRISMA (Preferred Reporting Items for Systematic Reviews and Meta-Analyses) statement. Initially, screening was conducted to exclude duplicate, irrelevant titles, and remaining abstracts. Subsequently, remaining full-text articles were independently screened by two authors for eligibility in the review. After, still as part of the eligibility process, some full-text articles were excluded if: they did not have statistical data on cases of UTI in their sample, did not give access to numbers and assessment of UTI cases, had inappropriate size sample $(\mathrm{n}<100)$, treatment duration with SGLT2i $<12$ weeks $(0,25$ years), or did not mention the method for UTI detection.

At the end of the selection, 23 studies were included for the proposed systematic review. The data for analysis were arranged in tables in Excel (Microsoft, version 15.3) to produce the results. Afterward, the data obtained were transferred to RevMan (Cochrane Collaboration, version 5.3) for statistical evaluation. The measure of association was the odds ratio (OR) and confidence interval (CI) of 95\%.

\section{RESULTS}

Twenty-three clinical trials, published between 2011 and 2016, were included and analyzed in the review. In these, the incidence of UTI was compared in patients with DM2 using SGLT2i versus the control group using a placebo or another antidiabetic of proven efficacy. The duration of SGLT2i treatment ranged from 0.5 to 2.6 years in the studies. In the selected articles, the following drugs used were: Dapagliflozin ${ }^{5-15}$, Canagliflozin ${ }^{16-20}$, Empagliflozin ${ }^{21-26,}$ and Tofogliflozin ${ }^{27}$. The characteristics of each study are in Table 1.

The profiles of the patients analyzed in the studies were those with DM2, using or not oral antidiabetic drugs or insulin, with or without associated comorbidities and of both genders. The total sample

FIGURE 1: FLOWCHART OF THE PROCESS FOR SYSTEMATIC REVIEW OF THE LITERATURE USING THE PRISMA (PREFERRED REPORTING ITEMS FOR SYSTEMATIC REVIEWS AND META-ANALYZES) STATEMENT.

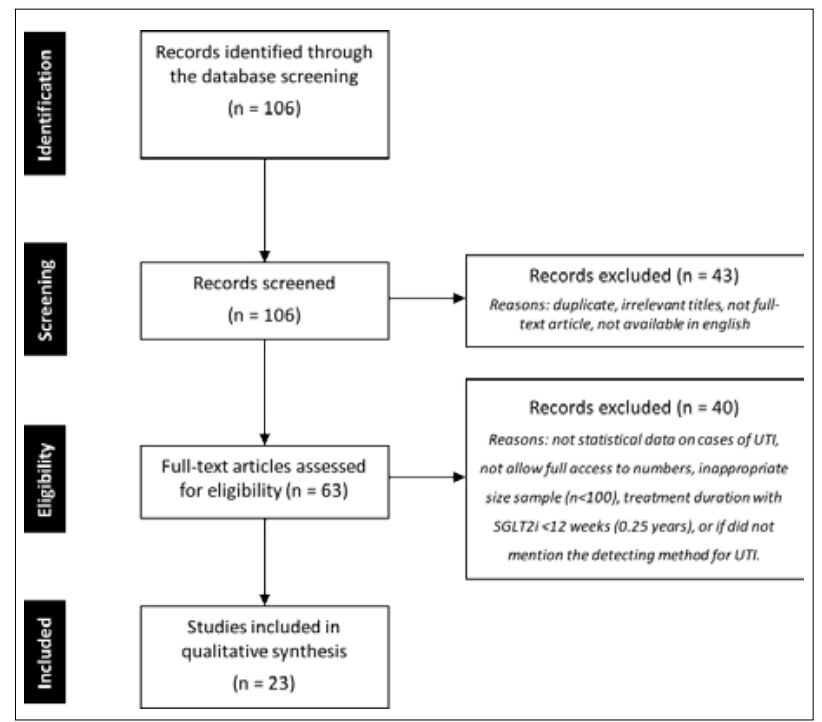


TABLE 1: CHARACTERISTICS OF THE STUDIES INCLUDED IN THE REVIEW.

\begin{tabular}{|c|c|c|c|c|c|}
\hline Author & Year & Sample & $\begin{array}{l}\text { SGLT2i ana- } \\
\text { lyzed }\end{array}$ & Sample characteristics & $\begin{array}{l}\text { Treatment } \\
\text { time }\end{array}$ \\
\hline Cefalu et al & 2013 & 1450 & Canagliflozin & Metformin use & 1 year \\
\hline Inagaki et al & 2014 & 272 & Canagliflozin & With and without medication and inadequate glycemic control & 0.5 year \\
\hline Neal et al & 2014 & 2072 & Canagliflozin & Risk of cardiovascular disease and inadequate glycemic control & 1 year \\
\hline Nicolle et all & 2012 & 451 & Canagliflozin & Metformin use & 0.25 year \\
\hline Nicolle et al & 2014 & 11752 & Canagliflozin & With or without oral antidiabetic & 2 years \\
\hline Bailey et al & 2014 & 167 & Dapagliflozin & With and without medication and inadequate glycemic control & 2.1 year \\
\hline Bolinder et al & 2012 & 182 & Dapagliflozin & Female postmenopausal and man (30-75 years) on Metformin & 0.5 year \\
\hline Bolinder et al & 2011 & 140 & Dapagliflozin & Female on Metformin use & 2.1 year \\
\hline Del Prato et al & 2015 & 814 & Dapagliflozin & Metformin use & 4.3 year \\
\hline Jabbour et al & 2014 & 451 & Dapagliflozin & With and without medication and inadequate glycemic control & 1 year \\
\hline ji et al & 2014 & 393 & Dapagliflozin & With and without medication and inadequate glycemic control & 0.5 year \\
\hline Leiter et al & 2014 & 965 & Dapagliflozin & With established cardiovascular disease & 1.08 year \\
\hline Nauk et al & 2013 & 814 & Dapagliflozin & Metformin associated or not to another oral antidiabetic & 1 year \\
\hline Rosenstock et al & 2012 & 420 & Dapagliflozin & Pioglitazona associated or not to another oral antidiabetic & 1 year \\
\hline Wilding et al & 2012 & 808 & Dapagliflozin & Obese in use of Insulin & 1 year \\
\hline Wilding et al & 2014 & 808 & Dapagliflozin & Use of up to 2 antidiabetics & 2.1 year \\
\hline Cherney et al & 2016 & 3215 & Empagliflozin & Micro or macroalbuminuria & 1 year \\
\hline Ferrannini et al & 2013 & 659 & Empagliflozin & Metformin use or not & 0.25 year \\
\hline Ridderstrale et al & 2014 & 1545 & Empagliflozin & Previous use of Metformin & 2 years \\
\hline Rosenstock et al & 2014 & 563 & Empagliflozin & Obese in use of Insulin associated or not with Metformin & 1 year \\
\hline Rosenstock et al & 2013 & 495 & Empagliflozin & Previous use of antidiabetic & 0.25 year \\
\hline Zinman et al & 2015 & 7020 & Empagliflozin & Cardiovascular disease without treatment with antidiabetic & 2.6 years \\
\hline Ikeda et al & 2015 & 394 & Tofogliflozin & With and without medication and inadequate glycemic control & 0.25 year \\
\hline
\end{tabular}

for review was of 25,736 patients, and in the studies, the largest sample was 11,572 patients and the lowest 140 , with a mean of 1,118 patients per study.

Together, the studies showed an increase in the chance of UTI in the SGLT2i group compared to the placebo (SGLT2i 2,133 of 23,594 [0.09\%] versus placebo [0.08\%], OD 1.18; 1.03-1.34; $\mathrm{p}=0.02$ ), (Figure 2). The $\mathrm{I}^{2}$ index of the Higgins Inconsistency Test in this analysis was $32 \%$, indicating moderate heterogeneity of the sample. In addition, individual UTI trends in patients using SGLT2i were noted in the individual analyzes of the studies. ${ }^{1-13}$ There was no evidence of publication bias observed by statistically constructed Funnel Plot.

In addition, we analyzed the incidence of UTI in different subgroups: in patients on SGLT2i monotherapy or in combination therapy, according to specific comorbidities of each sample, and according to each drug used.

Six articles analyzed patients on SGLT2i monotherapy ${ }^{5,9,15,17,21,22}$ and fourteen used patients on SGLT2i in combination with another oral antidiabetic agent $^{6,8,9,11,14,16,20-25,27,28}$; most of the associations were with Metformin. The odds of developing UTI in both monotherapy and combination therapy were higher in the group using SGLT2i compared to the placebo (monotherapy: OD 1.24; 0.88-1.77; $\mathrm{p}=0.22$; combined therapy: OD $1.24 ; 0.94-1.64 ; p=0.13)$.

Two studies analyzed the adverse effects of SGLT2i in patients on insulin therapy ${ }^{13,28}$. Both used obese patients in the sample. SGLT2i was associated with insulin alone or with Metformin. For the combined use of insulin and Metformin, there was no difference in the chance of UTI in patients compared to the placebo (OD 1.0; 0.62-1.63; $p=0.48)^{28}$. For the association of SGLT2i with insulin, however, there was an increased chance of UTI in the experimental group (OD 1.70; 0.78-3.70; $p=0.48)^{13}$. Statistical analysis of the studies together showed an increase in the chance of UTI with SGLT2i compared to the placebo (OD 1.19; 0.73-1.95; $\mathrm{p}=0.48$ ).

In patients with an established cardiovascular disease or with risk factors for the development of this pathology, there was also an increased chance of UTI in the group using SGLT2i (OD 1.17; 0.81-1.69; $p=0.4$ ). Samples with these characteristics were selected in three studies ${ }^{10,18,26 .}$ However, these showed marked heterogeneity among them $\left(I^{2}=72 \%\right)$.

One study observed the risk of UTI in 3215 patients with microalbuminuria or macroalbumin- 
uria in use of SGLT2 ${ }^{21}$. In this study, there was no increased chance of UTI in patients on SGLT2i compared to the placebo (OD 0.93; 0.58-1.49; $\mathrm{p}=0.75$ ).

Separate analysis of the drugs showed an increased chance of UTI in the groups using Dapagliflozin, Canagliflozin, and Tofogliflozin, regardless of the dose taken (OD 1.67; 1.35-2.08; $\mathrm{p}<0.00001$; OD 1.15; 1.01-1.32; p=0.04; OD 1.63; 0.20-13.22; $\mathrm{p}=0.65$, respectively). Only the Empagliflozin did not demonstrate an increased chance of UTI in comparison with the placebo (OD 0.95; 0.85-1.06; $\mathrm{p}=0.39$ ) in the studies. However, one article included in the review showed that when Empagliflozin is used at a $50 \mathrm{mg}$ dose, there was an increased chance of developing UTI (OD 1.57; 0.25-9.69; p=0.63). However, in this same study, there was also an increased chance when the drug was used at lower doses ${ }^{25}$. The characteristics of the drugs analysis on each study are shown in Figure 3.

\section{DISCUSSION}

Diabetic patients have an increased incidence of UTI compared to non-diabetic patients and present a increased severity of the disease. Diabetic women present bacterial cystitis, asymptomatic bacteriuria, and symptomatic UTI associated with complications, more frequently than non-diabetic women, with an estimated risk four times higher. A possible explanation for this risk in diabetics is in the physiopathology, in which the high levels of glucose in the urine can promote bacterial growth. In addition, the restriction of the peripheral blood circulation caused by prolonged diabetes can cause abnormalities in the defense system, increase the probability of infections and gravity of this condition. ${ }^{29,30}$

Glycosuria induced by SGLT2i, therefore, has been avidly researched in correlation with the infectious processes of the genito-urinary tract. Revision studies have shown an increase in the occurrence of genital infection in men and women using SGLT2i. 29,30 Regarding UTI's, some recent reviews have shown, based on trial analysis, that patients treated with SGLT2i may have a slightly increased risk of developing UTI. The results demonstrated in our study corroborate such analyzes. We compared our study to the 2016 review conducted by Rizzi and Trevis$\mathrm{an}^{29}$ that applied a similar methodology to evaluate, among other genito-urinary infections, UTI correlated with the use of SGLT2i in diabetic patients.

FIGURE 2: CHANCES OF URINARY TRACT INFECTION (REPRESENTED BY "EVENTS" IN THE CHART) IN PATIENTS WITH SGLT2I USE VERSUS THE CONTROL GROUP IN THE STUDIES INCLUDED. THE CHART ACCOMPANIES THE FORREST PLOT. ABBREVIATIONS: SGLT2I MEANS COTRANSPORTER-2 SODIUM-GLUCOSE INHIBITORS; CI, CONFIDENCE INTERVAL; I²CORRESPONDS TO THE INDEX OF THE HIGGINS INCONSISTENCYTEST IN THIS ANALYSIS.

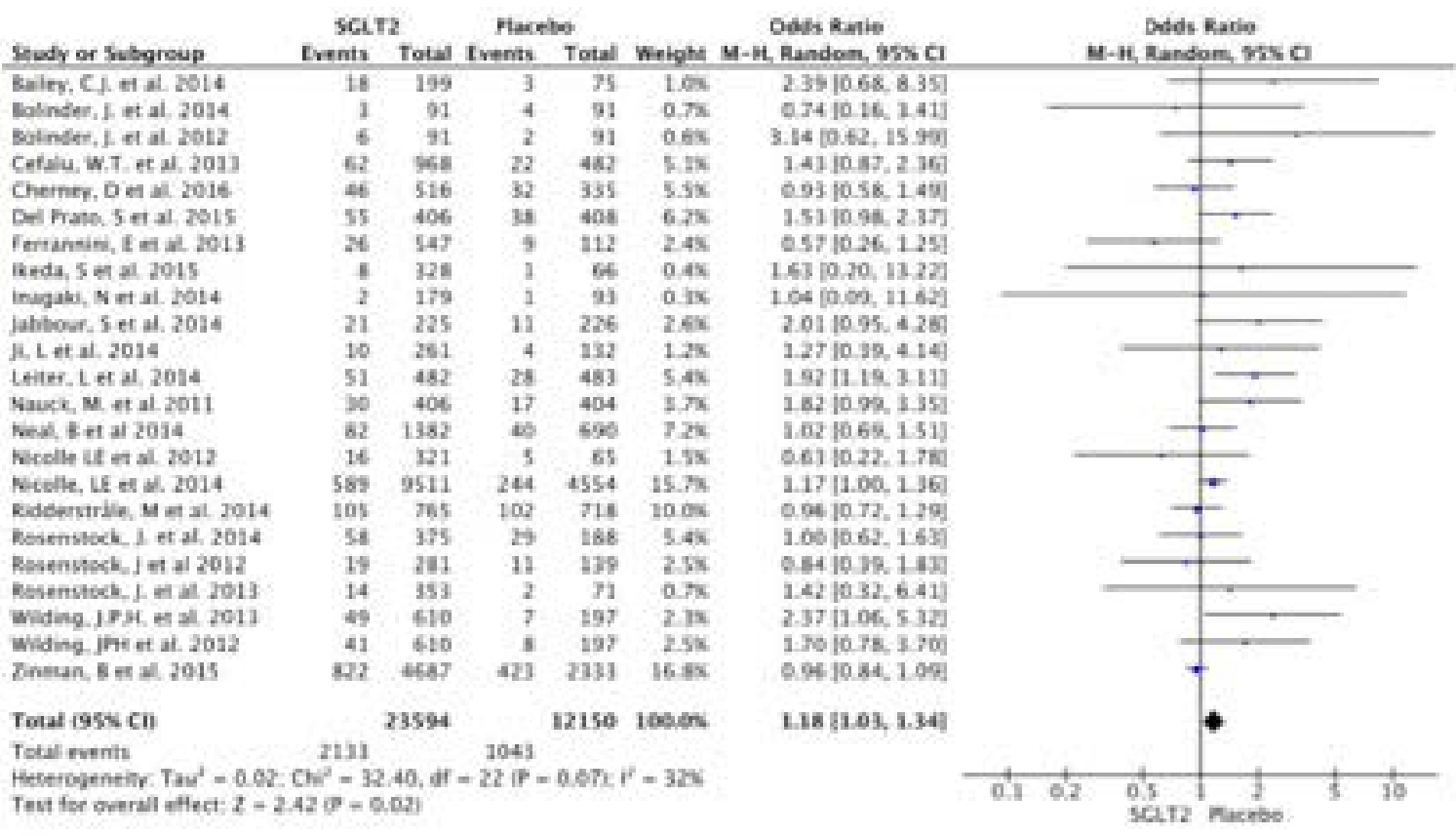


FIGURE 3: CHANCES OF URINARY TRACT INFECTION (REPRESENTED BY "EVENTS" IN THE CHART) IN PATIENTS WITH SGLT2I USE VERSUS A CONTROL GROUP, GROUPED ACCORDING TO THE DRUG ANALYZED IN EACH STUDY. THE CHARTS ACCOMPANY THE FORREST PLOTS CORRESPONDENCE IN (A) CANAGLIFLOZIN, (B) DAPAGLIFLOZIN, (C) EMPAGLIFLOZIN, AND (D) TOFOGLIFLOZIN. ABBREVIATIONS: SGLT2I MEANS COTRANSPORTER-2 SODIUMGLUCOSE INHIBITORS; CI, CONFIDENCE INTERVAL; I2 CORRESPONDS TO THE INDEX OF THE HIGGINS INCONSISTENCY TEST IN THIS ANALYSIS.

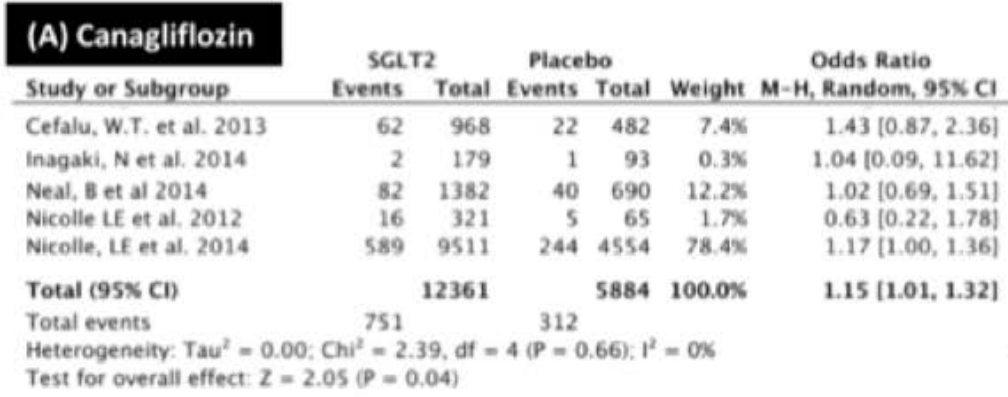

\section{(B) Dapagliflozin}

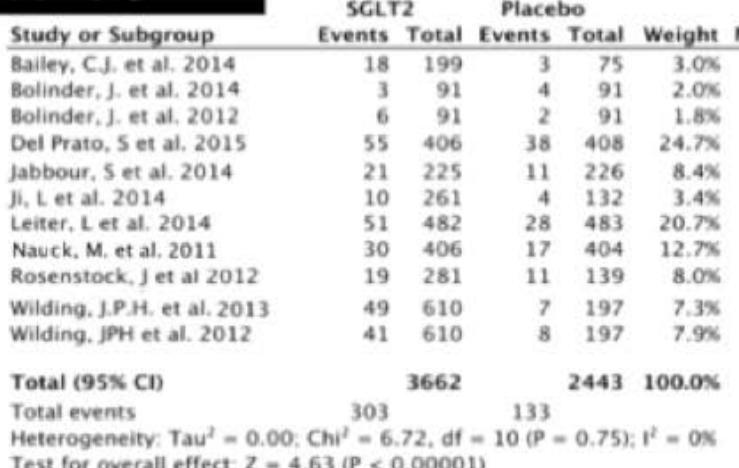

Odds Ratio

Random, 95\% CI $2.39[0.68,8.35]$ $0.74 \mid 0.16,3.41]$ $3.14[0.62,15.99]$ $1.53[0.98,2.37]$ $2.01[0.95,4.28]$ $1.27[0.39,4.14]$ $-92[1.19,3.11]$ $1.82[0.99,3.35]$ $0.84[0.39,1.83]$ $2.37[1.06,5.32]$ $1.70\lceil 0.78,3.70 \mid$

$1.67[1.35,2.08]$ Test for overall effect $Z=4.63$ (P $<0.00001$ )

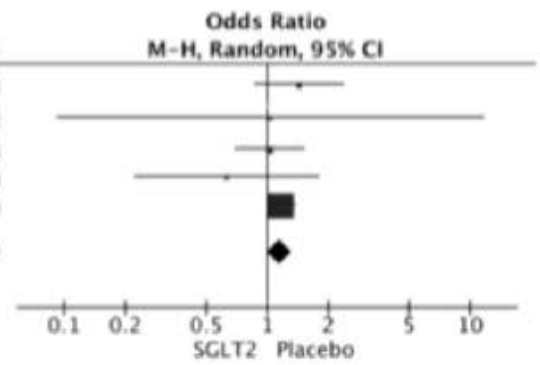

Odds Ratio

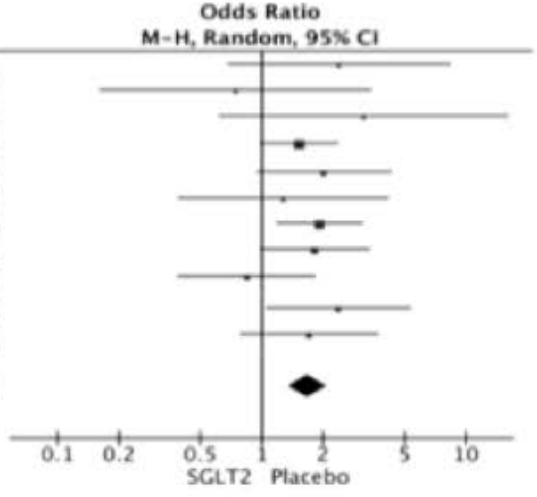

\section{(C) Empagliflozin}

Study or Subgroup Cherney, D et at. 2016 Ferrannini, E et al. 2013

SGLT2 Placebo Ridderstrale. M et al. 2014 Rosenstock, I. et al. 2014 Rosenstock, J. et al. 2013 Zinman, B et al. 2015

$\begin{array}{rrrrr}46 & 516 & 32 & 335 & 5.4 \%\end{array}$
Random, 95\% Ci $0.93[0.58,1.49]$ $0.57[0.26,1.25]$ $\begin{array}{lllll}26 & 547 & 9 & 112 & 205\end{array}$ $\begin{array}{lllll}105 & 765 & 102 & 718 & 14.18\end{array}$ $\begin{array}{lllll}58 & 375 & 29 & 188 & 5.28\end{array}$ $\begin{array}{lllll}14 & 353 & 2 & 71 & 0.58\end{array}$ Total (95\% CI) $822 \quad 4687$ $0.96[0.72,1.29]$ $1.00[0.62,1.63]$ $1.42[0.32,6.41]$ $0.96[0.84,1.09]$ $\begin{array}{rrr}7243 & 3757 \quad 100.0 \mathrm{x}\end{array}$ Heterogeneity: $\mathrm{Tau}^{2}=0.00 ; \mathrm{Chi}^{2}=1.97$, df $=5(\mathrm{P}=0.85) ; \mathrm{I}^{2}=0 \mathrm{x}$ Test for overall effect: $Z=0.86(P=0.39)$

$0.95[0.85,1.06]$

\section{(D) Tofogliflozin}

\begin{tabular}{|c|c|c|c|c|c|c|}
\hline Study or Subgroup & $\begin{array}{l}\text { SGLT } \\
\text { Events }\end{array}$ & $\begin{array}{l}2 \\
\text { Total }\end{array}$ & $\begin{array}{l}\text { Place } \\
\text { Events }\end{array}$ & Total & Weight & $\mathrm{M}-\mathrm{H}$, Random, $95 \% \mathrm{CI}$ \\
\hline Ikeda, 5 et al. 2015 & 8 & 328 & 1 & 66 & $100.0 \%$ & $1.63[0.20,13.22]$ \\
\hline Total $(95 \times \mathrm{CD})$ & & 328 & & 66 & $100.0 \%$ & $1.63[0.20,13.22]$ \\
\hline $\begin{array}{l}\text { Total events } \\
\text { Heterogeneity: Not } \\
\text { Test for overall effe }\end{array}$ & $(p=$ & & 1 & & & \\
\hline
\end{tabular}
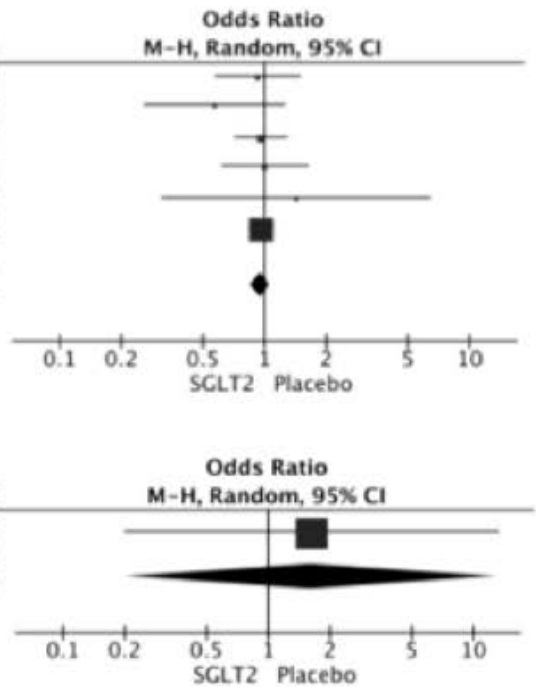

Studies matching Canagliflozin have shown that the chances of developing UTI are greater with the use of this inhibitor than it was with the placebo. There was a relationship with the dose of Canagliflozin, with a greater risk in patients who use 300mg per day than in patients who use 100mg per day. ${ }^{30}$ In our study, we observed an increased risk of UTI in patients who used Canagliflozin compared to the placebo, but we found no association with the dosing. It has been shown that patients treated with Da- 
pagliflozin may be at increased risk of UTI compared to the placebo group. The comparative difference was in the dose of the drug. While in the Rizzi and Trevisan ${ }^{29}$ study the dose of 2,5mg Dapagliflozin per day was associated to a lower risk of UTI than the placebo, in our study, we found no significant relationship between the risk of UTI and the dose of Dapagliflozin.

As for Empagliflozin, studies have shown an increased probability of developing UTI in comparison with the placebo, except at a dose of $5 \mathrm{mg}$ per day, for which the chances of UTI were much lower than the placebo. ${ }^{30}$ Our study showed that Empagliflozin does not present a risk of increased UTI when compared to the placebo at doses of 5,10 , or $25 \mathrm{mg}$ per day. A single study in our sample experimented with $50 \mathrm{mg}$ of Empagliflozin and found an increase of UTI at all doses tested (10, 25, $50 \mathrm{mg} /$ day)..$^{25}$

As for Togogliflozin, no review study evaluated its relationship with UTI. In our study, we included a single article focusing on this drug. It was found an elevated risk of developing UTI with SGLT2i in comparison with the placebo, although we did not see any dose relationship in the analyses.

Regarding the associations of SGLT2i with other oral antidiabetics in treatment, we found there is a superior chance of developing UTI in comparison with the placebo when the patient was in combination therapy.

There were no statistically significant results regarding the incidence of UTI among the different groups of patients analyzed: in monotherapy, in combined therapy, and insulin therapy; or in relation to associated clinical comorbidities, such as cardiovascular diseases and presence of renal injury (micro and macroalbuminuria).

Some limitations found limited the studies ana- lyzed. The main limitation was in the diagnosis of UTI proposed in the methodology of the trials. We excluded the records that did not identify methods of detection of UTI in the methodology. Most studies used pre-specified queries, using lists of preferred terms from the Medical Dictionary for Regulatory Activity (MedDRA) to determine UTI in patients. Looking for evidence on the effectiveness and safety of the drugs, the trials did not focus on the procedures to detect UTI in their samples. Since there was a clinical identification through the symptoms reported by the patients during the period of treatment with SGLT2i, the possibility of these patients already having ITU prior to the start of the treatment has not been clearly excluded. This is an important fact since this comorbidity already has a high prevalence in diabetic patient.

\section{CONCLUSIONS}

Diabetic patients treated with SGLT2i had an increased chance of developing UTI compared to those who did not use it. This increased chance was found predominantly with the use of Dapagliflozin, Canagliflozin, and Tofogliflozin, regardless of the dosing. However, the dimension of UTI chances for the DM2 patients in use of these drugs still remains to be more strictly determined. The currently increased use of SGLT2i in clinical practice an requires an analysis of urinary disorders, such as excluding the presence of UTI prior to the treatment, and the elaboration of more specific diagnostic methods for this pathology. These are imperative to determinate the long-term impact of increases in UTI episodes with SGLT2i use.

\section{Conflict of Interest}

The authors have no conflict on interest in this review.

\section{RESUMO}

Os inibidores do cotransportador de sódio-glicose do tipo 2 (SGLT2i) são medicamentos que atuam mantendo a glicosúria. Estudos recentes têm demonstrado efeitos promissores desses no tratamento de diabetes mellitus tipo 2(DM2). No entanto, pode haver um risco aumentado de desenvolver infecções do trato urinário (UTI) em pacientes tratados com essa classe de medicação. Nosso estudo tem como objetivo analisar a associação entre o risco de desenvolver UTI em pacientes tratados com SGLT2i. Uma revisão sistemática da literatura foi realizada por ensaios clínicos randomizados, totalizando, ao final da seleção, 23 artigos que foram avaliados estatisticamente. A incidência de UTI foi demonstrada genericamente de acordo com os dados dos artigos e em diferentes subgrupos: pacientes em monoterapia com SGLT2i ou em terapia combinada, de acordo com as comorbidades específicas de cada amostra ou de acordo com a droga utilizada. Verificou-se um aumento na chance de UTI nos grupos SGLT2i em comparação com os grupos de controle em placebo ou outros agentes antidiabéticos orais. Essa chance aumentada foi encontrada predominantemente com uso de Dapagliflozina, Canagliflozina e Tofoglifozina, independentemente da dosagem. Por fim, ressaltou-se que as chances de UTI em pacientes com DM2 em uso de SGLT2i ainda precisam ser mais bem determinadas. 


\section{REFERENCES}

1. Dionisio LMC. Inibidores do co-transportador renal de sódio-glicose 2: uma nova classe terapêutica para o controlo de glicemia na diabetes [Dissertação de mestrado]. Porto: Faculdade de Ciências da Saúde, Universidade Fernando Pessoa; 2015.

2. Marcondes JAM. Diabete melito: fisiopatologia e tratamento. Rev Fac Ciênc Méd Sorocaba. 2003;5(1):18-26.

3. Vivian EM. Dapagliflozin: a new sodium-glucose cotransporter 2 inhibitor for treatment of type 2 diabetes. Am J Health Syst Pharm. 2015;72(5):36172.

4. Bailey Cl, Morales Villegas EC, Woo V, Tang W, Ptaszynska A, List IF. Efficacy and safety of dapagliflozin monotherapy in people with type 2 diabetes: a randomized double-blind placebo-controlled 102-week trial. Diabet Med. 2014;38(4):531-41.

5. Bolinder J, Ljunggren Ö, Johansson L, Wilding J, Langkilde AM, Sjöström $C D$, et al. Dapagliflozin maintains glycaemic control while reducing weight and body fat mass over 2 years in patients with type 2 diabetes mellitus inadequately controlled on metformin. Diabetes Obes Metab. 2014;16(2):159-69.

6. Bolinder J, Ljunggren Ö, Kullberg J, Johansson L, Wilding J, Langkilde AM, et al. Effects of dapagliflozin on body weight, total fat mass, and regional adipose tissue distribution in patients with type 2 diabetes mellitus with inadequate glycemic control on metformin. J Clin Endocrinol Metab. 2012;97(3):1020-31.

7. Del Prato S, Nauck M, Durán-Garcia S, Maffei L, Rohwedder K, Theuerkauf $\mathrm{A}$, et al. Long-term glycaemic response and tolerability of dapagliflozin versus a sulphonylurea as add-on therapy to metformin in patients with type 2 diabetes: 4-year data. Diabetes Obes Metab. 2015;17(6):581-90.

8. Jabbour SA, Hardy E. Dapagliflozin is effective as add-on therapy to sitagliptin with or without metformin: a 24-week, study. Diabetes Care. 2014;37(3):740-50

9. Leiter LA, Cefalu WT, Bruin TW, Gause-Nilsson I, Sugg |, Parikh SI. Dapagliflozin added to usual care in individuals with type 2 diabetes mellitus with preexisting cardiovascular disease: a 24-week, multicenter, randomized, double-blind, placebo-controlled study with a 28-week extension. Am Geriatr Soc. 2014;62(7):1252-62

10. Nauck MA, Prato SDP, Meier JJ, Durán-García S, Rohwedder K, Elze M, et al. Dapagliflozin versus glipizide as add-on therapy in patients with type 2 diabetes who have inadequate glycemic control with metformin: a randomized, 52-week, double-blind, active-controlled noninferiority trial. Diabetes Care. 2011;34(9):2015-22

11. Rosenstock J, Aggarwal N, Polidori D, Zhao Y, Arbit D, Usiskin K, et al Canagliflozin DIA 2001 Study Group. Dose-ranging effects of canagliflozin, a sodium-glucose cotransporter 2 inhibitor, as add-on to metformin in subjects with type 2 diabetes. Diabetes Care. 2012;35(6):1232-8.

12. Wilding JP, Woo V, Soler NG, Pahor A, Sugg J, Rohwedder K, et al; Dapagliflozin 006 Study Group. Long-term efficacy of dapagliflozin in patients with type 2 diabetes mellitus receiving high doses of insulin: a randomized trial. Ann Intern Med. 2012;156(6):405-15.

13. Wilding JP, Woo V, Rohwedder K, Sugg J, Parikh S; Dapagliflozin 006 Study Group. Dapagliflozin in patients with type 2 diabetes receiving high doses of insulin: efficacy and safety over 2 years. Diabetes Obes Metab. 2013;16(2):124-36.

14. Ji L, Ma J, Li H, Mansfield TA, T'joen CL, lqbal N, et al. Dapagliflozin as monotherapy in drug-naive Asian patients with type 2 diabetes mellitus: a randomized, blinded, prospective phase III study. Clin Ther. 2014;36(1):84100.

15. Cefalu WT, Leiter LA, Yoon KH, Arias P, Niskanen L, Xie J, et al. Efficacy and safety of canagliflozin versus glimepiride in patients with type 2 diabetes inadequately controlled with metformin (CANTATA-SU): 52 week results from a randomised, double-blind, phase 3 non-inferiority trial. Lancet. 2013:382(9896):941-50.
16. Inagaki N, Kondo K, Yoshinari T, Takahashi N, Susuta Y, Kuki H. Efficacy and safety of canagliflozin monotherapy in lapanese patients with type 2 diabetes inadequately controlled with diet and exercise: a 24-week, randomized, double-blind, placebo-controlled, Phase III study. Expert Opin Pharmacother. 2014;15(11):1501-15.

17. Neal B, Perkovic V, Zeeuw D, Mahaffey KW, Fulcher G, Ways K, et al. Efficacy and safety of canagliflozin, an inhibitor of sodium-glucose cotransporter 2, when used in conjunction with insulin therapy in patients with type 2 diabetes. Diabetes Care. 2014;38(3):403-11.

18. Nicolle LE, Capuano G, Fung A, Usiskin K. Urinary tract infection in randomized phase III studies of canagliflozin, a sodium glucose co-transporter 2 inhibitor. Postgrad Med. 2014;126(1):7-17.

19. Nicolle LE, Capuano G, Ways K, Usiskin K. Effect of canagliflozin, a sodium glucose co-transporter 2 (SGLT2) inhibitor, on bacteriuria and urinary tract infection in subjects with type 2 diabetes enrolled in a 12-week, phase 2 study. Curr Med Res Opin. 2012;28(7):1167-71.

20. Cherney D, Lund SS, Perkins BA, Groop P, Cooper ME, Kaspers S, et al. The effect of sodium glucose cotransporter 2 inhibition with empagliflozin on microalbuminuria and macroalbuminuria in patients with type 2 diabetes. Diabetologia. 2016;59(9):1860-70.

21. Ferrannini E, Berk A, Hantel S, Pinnetti S, Hach T, Woerle HI, et al. Longterm safety and efficacy of empagliflozin, sitagliptin, and metformin: an active-controlled, parallel-group, randomized, 78-week open-label extension study in patients with type 2 diabetes. Diabetes Care. 2013;36(12):4015-21.

22. Ridderstråle M, Anderson KR, Zeller C, Kim G4, Woerle HJ4, Broedl UC4; EMPA-REG H2H-SU trial investigators. Comparison of empagliflozin and glimepiride as add-on to metformin in patients with type 2 diabetes: a 104-week randomised, active-controlled, double-blind, phase 3 trial. Lancet Diabetes Endocrinol. 2014;2(9):691-700.

23. Rosenstock J, Jelaska A, Frappin G, Salsali A, Kim G, Woerle HJ, et al; EMPA-REG MDI Trial Investigators. Improved glucose control with weight loss, lower insulin doses, and no increased hypoglycemia with empagliflozin added to titrated multiple daily injections of insulin in obese inadequately controlled type 2 diabetes. Diabetes Care. 2014;37(7):1815-23.

24. Rosenstock J, Seman LI, Jelaska A, Hantel S, Pinnetti S, Hach T, et al. Efficacy and safety of empagliflozin, a sodium glucose cotransporter 2 (SGLT2) inhibitor, as add-on to metformin in type 2 diabetes with mild hyperglycaemia. Diabetes Obes Metab. 2013;15(12):1154-60.

25. Zinman B, Wanner C, Lachin JM, Fitchett D, Bluhmki E, Hantel S, et al; EMPA-REG OUTCOME Investigators. Empagliflozin, cardiovascular outcomes, and mortality in type 2 diabetes. N Engl | Med. 2015;373(22):211728.

26. Ikeda S, Takano Y, Cynshi O, Tanaka R, Christ AD, Boerlin V, et al. A novel and selective sodium-glucose cotransporter-2 inhibitor, tofogliflozin, improves glycaemic control and lowers body weight in patients with type 2 diabetes mellitus. Diabetes Obes Metab. 2015;17(10):984-93.

27. Rosenstock J, Vico M, Wei L, Salsali A, List JF. Effects of dapagliflozin, an SGLT2 Inhibitor, on $\mathrm{HbA}(1 \mathrm{c})$, body weight, and hypoglycemia risk in patients with type 2 diabetes inadequately controlled on pioglitazone monotherapy. Diabetes Care. 2012;35(7):1473-8.

28. Sewify M, Nair S, Warsame S, Murad M, Alhubail A, Behbehani K, et al. Prevalence of urinary tract infection and antimicrobial susceptibility among diabetic patients with controlled and uncontrolled glycemia in Kuwait. J Diabetes Res. 2016;2016:6573215.

29. Rizzi M, Trevisan R. Genitourinary infections in diabetic patients in the new era of diabetes therapy with sodium-glucose cotransporter-2 inhibitors. Nutr Metab Cardiovasc Dis. 2016;26(11):963-70.

30. Geerlings S, Fonseca V, Castro-Diaz D, List I, Parikh S. Genital and urinary tract infections in diabetes: impact of pharmacologically-induced glucosuria. Diabetes Res Clin Pract. 2014;103(3):373-81. 